\title{
The psychometric properties of the Mindful Attention Awareness Scale (MAAS) and Freiburg Mindfulness Inventory (FMI) as measures of mindfulness and their relationship with burnout and work engagement
}

\begin{tabular}{|c|c|}
\hline \multicolumn{2}{|c|}{$\begin{array}{l}\text { Authors: } \\
\text { Martina Kotzé1 } \\
\text { Petrus } \mathrm{Nel}^{2}\end{array}$} \\
\hline \multicolumn{2}{|c|}{$\begin{array}{l}\text { Affiliations: } \\
{ }^{1} \text { Business School, } \\
\text { University of the Free State, } \\
\text { South Africa }\end{array}$} \\
\hline \multicolumn{2}{|c|}{$\begin{array}{l}{ }^{2} \text { Department of Industrial } \\
\text { Psychology, University of the } \\
\text { Free State, South Africa }\end{array}$} \\
\hline \multicolumn{2}{|c|}{$\begin{array}{l}\text { Corresponding auth } \\
\text { Martina Kotzé, } \\
\text { kotzem@ufs.ac.za }\end{array}$} \\
\hline \multicolumn{2}{|c|}{$\begin{array}{l}\text { Dates: } \\
\text { Received: } 15 \text { Apr. } 2016 \\
\text { Accepted: } 01 \text { Aug. } 2016 \\
\text { Published: } 25 \text { Oct. } 2016\end{array}$} \\
\hline \multicolumn{2}{|c|}{$\begin{array}{l}\text { How to cite this article: } \\
\text { Kotzé, M., \& Nel, P. (2016). } \\
\text { The psychometric properties } \\
\text { of the Mindful Attention } \\
\text { Awareness Scale (MAAS) and } \\
\text { Freiburg Mindfulness } \\
\text { Inventory (FMI) as measures } \\
\text { of mindfulness and their } \\
\text { relationship with burnout } \\
\text { and work engagement. SA } \\
\text { Journal of Industrial } \\
\text { Psychology/SA Tydskrif vir } \\
\text { Bedryfsielkunde, 42(1), } \\
\text { a1366. http://dx.doi. } \\
\text { org/10.4102/sajip.v42i1.1366 }\end{array}$} \\
\hline \multicolumn{2}{|c|}{$\begin{array}{l}\text { Copyright: } \\
\text { (C) 2016. The Authors } \\
\text { Licensee: AOSIS. This } \\
\text { is licensed under the } \\
\text { Creative Commons } \\
\text { Attribution License. }\end{array}$} \\
\hline \multicolumn{2}{|l|}{ Read online: } \\
\hline 口ition: & $\begin{array}{l}\text { Scan this QR } \\
\text { code with your } \\
\text { smart phone or } \\
\text { mobile device } \\
\text { to read online. }\end{array}$ \\
\hline
\end{tabular}

Orientation: Given the increasing interest in mindfulness in the workplace, recent research recommends that the psychometric properties of existing mindfulness measures be evaluated in terms of convergent and predictive validity.

Research purpose: The research purpose was to assess the psychometric properties of the 15item (short version) Mindful Attention Awareness Scale (MAAS) and the 14-item (short version) Freiburg Mindfulness Inventory (FMI) in parallel on a South African sample. Furthermore, the research aimed to investigate the convergent validity between the FMI and MAAS as well as their relationship to burnout and work engagement (predictive validity).

Motivation for the study: Organisational scholars must investigate the most appropriate instruments for measuring mindfulness in the workplace. Doing so would allow an eventual meta-analysis on the construct and its relationships and utility in the workplace.

Research design, approach and methodology: For this study, a quantitative cross-sectional survey research design was employed. Convenience sampling was chosen and 497 participants applying for admission to a management and leadership degree programme at a South African Business School participated in the study. All participants of the sample are employed at either private or public institutions. Confirmatory factor analysis was used to determine the convergent validity of the instruments. Cronbach's alpha was utilised in determining the reliabilities of the instruments. The product-moment correlation by Pearson was used to compare the two instruments in terms of their relationship to burnout and work engagement. Stepwise multiple regression was used to determine whether the FMI and MAAS are significant predictors of burnout and work engagement (predictive validity).

Main findings: The results showed that the short versions of both the FMI and the MAAS are valid and reliable unidimensional measures of mindfulness. The findings showed that the two instruments are moderately correlated, providing adequate evidence of convergent validity. With regards to predictive validity, both the FMI and MAAS showed statistically significant relations with burnout and work engagement. Yet, the MAAS showed higher correlations with these constructs. A similar picture emerged with regards to the stepwise multiple regression results. The MAAS was the only significant predictor of burnout, explaining 12\% of the variance. Both the MAAS and FMI were significant predictors of work engagement. The MAAS explained 13\% of the variance in work engagement while the FMI explained 3\% of the variance.

Practical/managerial implications: Given these results, the MAAS currently seems to be a more appropriate measurement of mindfulness in the workplace given its ability to better predict work engagement and burnout than the FMI.

Contribution/value-add: The study has provided much needed empirical evidence on the psychometric properties of the FMI and MAAS as measures of mindfulness on a South African sample.

\section{Introduction}

Mindfulness is central in Buddhist teachings and denotes an attentive state of perceiving mental content, that is, the individual's perceptions, sensory input, thoughts and feelings (Walach, Buchheld, Buttenmüller, Kleinknecht \& Schmidt, 2006). Although the construct of mindfulness 
has its roots in Eastern contemplative traditions (Shapiro, Carlson, Astin \& Freedman, 2006), Western psychology has taken serious note of the concept (Christopher, Christopher \& Charoensuk, 2009). In psychological terms, mindfulness is described as 'an awareness that emerges through paying attention on purpose, in the present moment, and nonjudgementally to the unfolding of experience moment by moment' (Kabat-Zinn, 2003, p. 145). Mindfulness varies within a person from one moment to the next. Yet, a substantial amount of evidence exists which shows that there are established differences in mindfulness within an individual (Brown \& Ryan, 2003). Those higher in trait mindfulness are more frequently attentive to and aware of their inner experience and behaviour and are more able or willing to perceive internal and external realities openly and without distortion (Brown \& Ryan, 2003). Furthermore, various authors agree that mindfulness can be developed and enhanced through training (Leroy, Anseel, Dimitrova \& Sels, 2013). For example, a recent study has shown that workplace mindfulness training resulted in teachers reporting fewer bad moods at work as well as better sleeping patterns (Crain, Schonert-Reichl \& Roeser, 2016).

Mindfulness training has also been found to have a positive effect on well-being-related outcomes, such as 'the experience of positive emotions, coping capabilities, and purposefulness in life' (Leroy et al., 2013, p. 239). Furthermore, mindfulness has been linked to both decreased emotional exhaustion (Hülsheger et al., 2013) and increased employee engagement (Leroy et al., 2013). Because of the growing interest in the concept of mindfulness in business, government and academia (Hyland, Lee \& Mills, 2015), mindfulness has also been investigated in the organisational and management fields (Dane \& Brummel, 2013; Hyland et al., 2015; Roche, Haar \& Luthans, 2014). These researchers claim that we must consider what impact mindfulness has on employees from a variety of work environments (Dane \& Brummer, 2013). Previous research has empirically related mindfulness to various work outcomes such as task performance, academic performance, problem solving, turnover intention, resilience and social relationships, burnout and work engagement, respectively ( $c f$. Dane, 2011; Dane \& Brummel, 2013; Glomb, Duffy, Bono \& Yang, 2011; Hülsheger, Alberts, Feinholdt \& Lang, 2013; Leroy et al., 2013; Roeser et al., 2013).

\section{Purpose and objectives of the study}

In shifting contexts from religion to psychotherapy and ultimately to the workplace, the meaning of mindfulness has been tailored to fit scientific ideals common to the Western world, and this has resulted in a situation where 'operationalizations of mindfulness have been constructed with an eye toward deconstructing specific components' (Christopher et al., 2009, p. 3). Subsequently, the relevance of these tailored operationalisations of the concept has become an issue for debate. Regarding the nature of mindfulness, there is agreement among writers, but it seems there is some confusion about what mindfulness is and is not (Dane, 2011). Most definitions of mindfulness focus on attention to experience as it occurs from one moment to the next. Nevertheless, many do not include all aspects of mindfulness as originally defined by Eastern philosophers (Grossman, 2008). Furthermore, there are prominent differences between self-report scales derived from these definitions. These measures of mindfulness make use of different definitions, and their complexity varies so that self-report scales may involve a single factor (Brown \& Ryan, 2003; Walach et al., 2006) or up to five factors (Baer, Smith, Hopkins, Krietemeyer \& Toney, 2006). Mindfulness has also been measured using instruments which measure a range of factors including mindlessness (Brown \& Ryan, 2003) and flexibility (Hyland et al., 2015).

A stable platform needs to be devised for basic and applied research in this new research area. Thus, researchers emphasise the need to reach consensus on the concept mindfulness and to develop psychometrically sound methods for assessing mindfulness (Bishop et al., 2004; Brown \& Ryan, 2003; Brown, Ryan \& Creswell, 2007). Hyland et al. (2015) argue that the similarities are more numerous than the differences across the definitions and mindfulness measures that currently exist. Walach et al. (2006) point out that we may assume that any instrument which measures the concept will capture some, but not all, of its aspects. Nevertheless, small differences can lead to construct validity concerns (Grossman, 2008; Hyland et al., 2015). These limitations of construct validity relate to the possible semantic interpretations of questionnaire items and contrasts between questionnaires (Grossman, 2008). External and criterion validity are also identified as limitations. External validity is problematic when generalising the findings from students to other populations while criterion validity is questioned when specific and objective external referents are not available in comparing the responses (Grossman, 2008). Researchers recommend that the psychometric properties, content and structure of existing mindfulness measures be evaluated (Hyland et al., 2015), while an analysis of different instruments in parallel is also desirable (Walach et al., 2006).

To determine the boundary conditions of mindfulness within the workplace, organisational scholars must investigate the most appropriate measuring instruments for this purpose. Doing so would facilitate individual studies on mindfulness and its effects in the workplace and allow an eventual metaanalysis on the construct and its relationships and utility in the workplace (Hyland et al., 2015).

According to Hyland et al. (2015), the two most popular psychometric measures of mindfulness in survey and experimental research are the Mindful Attention Awareness Scale (MAAS) (Brown \& Ryan, 2003) and the FMI (Buchheld, Grossman \& Walach, 2001). Therefore, this study investigates the psychometric properties of the MAAS and FMI and seeks to determine whether these instruments measure the same construct. Because well-being in the workplace, specifically burnout and engagement, has previously been empirically investigated in relation to mindfulness, these constructs are 
used as outcome variables to test whether the MAAS or FMI has higher correlations with these two outcome variables.

In light of the above, the objectives of the study are threefold, namely, to:

- compare the validity and reliabilities of the 15-item MAAS (short version) and 14-item FMI (short version) on a South African sample

- determine whether the 15-item MAAS and 14-item FMI show evidence of convergent validity and

- compare the 15-item MAAS and the 14-item FMI in terms of their relationship with burnout and work engagement (predictive validity).

A brief overview of the construct mindfulness and the measurement thereof follows, with specific reference to the FMI and MAAS. Burnout and work engagement, as possible outcomes of mindfulness, are also briefly discussed. Thereafter, the research design, the results and research outcomes as well as limitations and recommendations based on the research are discussed.

\section{Literature review}

\section{Mindfulness: Making meaning from the construct}

Mindfulness is defined differently by various practitioners, researchers and clinicians, as well as according to the various schools of thought, which place more emphasis on particular aspects of the concept compared to others (Brown et al., 2007). Dane (2011) provides a synopsis of various academic and philosophical conceptualisations of mindfulness showing that scholars display noticeably high consensus on the nature of mindfulness. One of the features common across multiple conceptualisations is that mindfulness is a state of consciousness (Brown \& Ryan, 2003). It refers to '... a heightened state of involvement and wakefulness or being in the present' (Langer \& Moldoveanu, 2000, p. 2). Brown, Kasser, Ryan, Linley and Orzech (2009) explain that mindfulness is not deliberative in nature. Inputs are allowed to enter one's awareness by simply noticing what is taking place. Mindfulness refers to the simple act of observing without scrutiny, making comparisons or evaluating events and experience and is thus dissimilar to 'self-awareness' or reflexive consciousness in other forms. Instead, mindfulness concerns a non-interference with experience. Walach et al. (2006, p. 1544) explain that it is 'a warm and friendly, accepting and non-judgemental attitude towards those elements of our mind. Suspending categorical judgements, which normally follow every perception rather quickly, is an integral part of mindfulness'. Therefore, mindfulness is not a cold, cognitive process.

Langer and Moldoveanu (2000, p. 4) state that a central aspect of mindfulness is 'sensitivity to the novel and, therefore, the unexpected', which keeps individuals 'situated in the present' (p. 7). Mindfulness permits greater awareness of the context and perceptions of actions than a reliance upon past notions. The process of extracting unique distinctions can have unexpected and novel results including 'greater sensitivity to one's environment', 'more openness to new information', 'the creation of new categories for structuring perception' and 'enhanced awareness of multiple perspectives in problem solving' (Langer \& Moldoveanu, 2000, p. 2).

A second commonality found in these different definitions of mindfulness relates to the notion that attention is focused on the present-moment phenomena. In other words, 'mindfulness helps people be in the present moment and accept it for what it is' (Leroy et al., 2013, p. 239). To be mindful, individuals must be attentive to the 'here and now', as 'opposed to being preoccupied with thoughts about the past or the future' (Dane, 2011, p. 3). As they are focusing on what is happening in the present moment, neither the past nor the future is of immediate concern to them. Mindfulness can be seen as pre-conceptual; allowing mindful individuals to be 'simply aware of and attend to what is happening in the present moment' (Depenbrock, n.d., p. 6). Therefore, mindful individuals stay in direct contact with reality.

Thirdly, mindfulness involves attending to external (environmental) and internal (intrapsychic) phenomena. Because the present moment includes both external and internal phenomena, a mere focus on external events to the exclusion of internal processes, or vice versa, would be indicative of a lack of mindfulness (Dane, 2011). Subsequently, Dane (2011, p. 4) defines mindfulness as 'a state of consciousness in which attention is focused on present-moment phenomena occurring both externally and internally'. Shapiro et al. (2006) propose that Intention, Attention and Attitude (IAA) are the three axioms of mindfulness. The role of attention in mindfulness practice relates to the ability to observe the operations of one's moment-tomoment, internal and external experience. Attitude relates to how we attend and the qualities one brings to attention. According to Shapiro et al. (2006), the state of mindfulness arises when IAA are simultaneously cultivated. The latter authors' opine that 'when Western psychology attempted to extract the essence of mindfulness practice from its original religious/ cultural roots' the aspect of intention was lost to a certain extent, which 'for Buddhism was enlightenment and compassion for all beings' (Shapiro et al., 2006, p. 375).

Furthermore, mindfulness is sometimes described as a type of mental process, a trait, a state of mind, or a learnable skill (Brown \& Ryan, 2003; Grossman, 2008). Dane (2011, p. 3) opines that, as a state, 'mindfulness is not a quality that some individuals possess and others lack'. The author further states that attaining a mindful state of consciousness 'is an inherent human capacity - a claim implying that most people have been or at least can be mindful at one point or another'. According to Brown et al. (2007, p. 218), there is evidence that dispositional mindfulness 'reflects a greater tendency to abide in mindful states over time'. Several studies have revealed dispositionbased differences in mindfulness across individuals (Baer et al., 2006; Dane \& Brummel, 2013; Lau et al., 2006). A study by Modinos, Ormel and Aleman (2010, p. 369) showed that individual differences in dispositional mindfulness, 'may modulate activity in neural systems involved in the effective cognitive control of negative emotion'. Therefore, some people 
may be in a mindful state of consciousness more often than others. This suggests that, mindfulness is fundamentally a state-level construct that can also be assessed at the trait level (Brown \& Ryan, 2003; Dane, 2011).

\section{Mindfulness measures}

A variety of measures of mindfulness have been constructed such as the MAAS (Brown \& Ryan, 2003), the FMI (Buchheld et al., 2001), the Toronto Mindfulness Scale (TMS) (Lau et al., 2006), the Kentucky Inventory of Mindfulness (KIMS) (Baer, Smith \& Allen, 2004), the Cognitive and Affective Mindfulness Scale (Feldman, Hayes, Kumar, Greeson \& Laurenceau, 2007) and the Southampton Mindfulness Questionnaire (Chadwick, Hember, Symes, Peters, Kuipers, \& Dagnan, 2008). These scales differ because some measure mindfulness as a unidimensional construct versus a multi-faceted construct (Baer et al., 2006), while others measure mindfulness as a trait-like or state-like construct (Dane, 2011). Some consider only the mental state, whereas others include bodily sensations and experience (Grossman, 2008). Furthermore, some measures (e.g. KIMS) include the reported ability to verbally describe experience (e.g. 'I am good at finding the words to describe my feelings'), while others emphasise a particular orientation of curiosity, openness and acceptance (e.g. TMS) (Grossman, 2008). According to Grossman (2008, p. 406), many developers of mindfulness inventories have a 'relatively modest level of personal experience with mindfulness meditation practices or Buddhist psychological theory', with little 'contributions from traditional mindfulness meditation experts'. Furthermore, the extent of meditation and mindfulness experience is likely to influence how items in mindfulness scales are understood and interpreted and may alter the meaning of words or items (Grossman, 2008).

As mentioned before, the FMI and the MAAS are the two most often used measures of mindfulness in survey and experimental research (Hyland et al., 2015). The FMI (Buchheld et al., 2001; Walach et al., 2006) arose from the Buddhist roots of mindfulness (Bergomi, Tschacher \& Kupper, 2012) and has a long (30-item) and a short form (14-item). The 30-item scale showed internal consistency with a Cronbach's $\alpha=0.93$ (Walach et al., 2006) and can demonstrate an increase in mindfulness after a retreat and discriminate between experienced and novice meditators. The validation study resulted in a four-factor structure (mindful presence, non-judgemental acceptance, openness to experiences and insight) (Walach et al., 2006). The developers of the FMI (Buchheld et al., 2001) suggested that although the FMI (full and short versions) consists of distinct components, it should be treated as a general (i.e. unidimensional) construct. Although both the full and the short versions of the FMI have consistently been found to be psychometrically sound (Hyland et al., 2015), some studies have questioned the factor structures of the two versions (Bergomi et al., 2012; Leigh, Bowen \& Marlatt, 2005).

The MAAS was developed by Brown and Ryan (2003), who define mindfulness as an open or receptive attention to and awareness of present events and experience. Therefore, the development of MAAS items centred on present-focused awareness as the foundation of mindfulness (Christopher et al., 2009). Brown and Ryan (2003) established the internal consistency of the measure $(\alpha=0.82)$, test-retest reliability ( $\alpha=0.82)$ and convergent validity with related measures (e.g. positive correlations with well-being). Originally, the MAAS consisted of a presence and acceptance factor. 'The acceptance factor was excluded in the final version' because the developers of the MAAS found it not to provide an explanatory advantage over that shown by the presence factor alone (Bergomi et al., 2012, p. 9). The one-dimensional structure of the MAAS has been replicated in several studies (Carlson \& Brown, 2005; MacKillop \& Anderson, 2007). Critics of the MAAS argue that the scale places too much focus on the attention and awareness aspects of mindfulness, while it excludes components such as acceptance, present focus and a non-judgemental state (Hyland et al., 2015; Walach et al., 2006). Also, some of the items of the MAAS 'may not be relevant to certain respondents or settings (e.g. "I drive places on 'automatic pilot' and then wonder why I went there")' (Dane \& Brummel, 2013, p. 10), while some permit a lack of differentiation across respondents (Van Dam, Earleywine \& Borders, 2010).

Because of practicalities and time constraints associated with conducting research in workplace settings, the usefulness of the short versions of the FMI and MAAS need to be determined.

\section{Mindfulness and work well-being (burnout and work engagement)}

Burnout is mostly described as having three separate but interrelated constructs: emotional exhaustion, depersonalisation and reduced personal accomplishment (Maslach \& Jackson, 1986; Maslach, Schaufeli \& Leiter, 2001). In the work environment, it manifests as exhaustion, cynical attitudes towards work and feelings of incompetence that occur because of chronic stress (Salanova, Schaufeli, Martinez \& Breso, 2009). Hülsheger et al. (2013) and others (Krasner et al., 2009; Oman, Richards, Hedberg \& Thoresen, 2008; Roeser et al., 2013) found that individuals who practice mindfulness are less inclined to experience emotional exhaustion.

Within a work setting, engagement is defined as a fulfilling, positive, affective-motivational state of well-being, leading to increased energy, higher levels of enthusiasm and a more task-focused approach (Macey \& Schneider, 2008). Work engagement includes three aspects namely, vigour, dedication and absorption (Schaufeli, Salanova, Gonzalez-Roma \& Bakker, 2002). Vigour is characterised by high levels of energy and a willingness to invest effort in one's work as well as persistence. Dedication is characterised by a feeling of enthusiasm and pride in one's work. Individuals who are dedicated to their jobs usually are inspired and challenged by it and derive a sense of significance from their work. Absorption is characterised by being immersed in one's work, enjoying it to such an extent that it is difficult to detach oneself from it (Schaufeli, Martinez, Pinto, Salanova \& Bakker, 2002). Workplace mindfulness differs from work engagement and its dimensions in the sense that mindfulness 
'is a cognitive construct concerned with the degree to which one's attention tends to be focused on a wide breadth of events unfolding in one's work context' (Dane \& Brummel, 2013, pp. 7-8). Vigour, dedication and absorption, on the other hand, implicate 'affective qualities that lack parallels with workplace mindfulness' (Dane \& Brummel, 2013, p. 8). Mindfulness can foster engagement by promoting heightened states of involvement and wakefulness in work activities (Leroy et al., 2013) and by assisting individuals to view existing activities in different, innovative and more interesting ways (Langer \& Moldoveanu, 2000). Leroy et al. (2013) conclude that mindfulness is important for strengthening the personal resources of work engagement.

\section{Research design Research approach}

The main purpose of the current study was to assess the validity of the factor structures and the reliabilities of both the 15-item MAAS and 14-item FMI on a South African sample. Furthermore, the study sought to determine the convergent validity between the MAAS and FMI as well as the predictive validity of the instruments with regards to burnout and work engagement. In order to execute the research, the current study employed a quantitative crosssectional design with a survey data collection technique.

\section{Research method}

\section{Participants}

A convenience sample of 497 participants applying for admission to a management and leadership degree at a South African Business School participated in the study. All participants of the sample were employed at either private or public institutions. Work experience and employment were essential criteria for admission to the business school. There was an almost equal split between the genders (females $=51.1 \%)$. The majority $(45 \%)$ of the sample was aged between 21 and 30 years, while $28 \%$ were aged between 31 and 40 years. Furthermore, 19\% were aged between 41 and 50 years. Only $8 \%$ were older than 50 years. Most of the participants $(53.5 \%)$ were employed in the private sector while $39.2 \%$ worked in the public sector. The remainder of the sample $(7.3 \%)$ were employed by NGOs.

\section{Measuring instruments}

In addition to the biographical assessment (as reported in the previous section), the current study distributed both the 15item MAAS and 14-item FMI to the participants.

MAAS: For the purposes of this study, the 15-item trait version of the MAAS (Brown \& Ryan, 2003) was used. The items reflect an 'absence of mindfulness' (Brown et al., 2009, p. 728). Therefore, higher scores on the 6-point Likert scale $(1=$ almost always to $6=$ almost never $)$ indicated greater mindfulness (Brown et al., 2009). Participants were asked to indicate how frequently or infrequently they have each experience. The total score was calculated by adding all the scores on the 15 items of the MAAS. The items included 'I find it difficult to stay focused on what's happening in the present' and 'I do jobs or tasks automatically, without being aware of what I'm doing' (Christopher et al., 2009, p. 2).

FMI: The short version of the FMI (FMI-14) was used. This scale was sensitive to change and was more appropriate for use in the general population and participants without meditation experience (Bergomi et al., 2012; Walach et al., 2006). Items included 'I am open to the experience of the present moment' and 'I am impatient with myself and with others' (Walach et al., 2006). Respondents indicate their experiences relating to the items on a 4-point Likert scale (rarely, occasionally, fairly often and almost always). The total score was calculated by adding all the scores on the 14 items of the FMI. Item 13 was reversed scored, as it was worded negatively in the FMI-14. Higher scores indicate higher levels of mindfulness.

Well-being: Well-being was measured using relevant items from the Maslach's Burnout Inventory (MBI-GS) (Schaufeli, Martinez, Pinto, Salanova \& Bakker, 2002) as well as relevant items from the Utrecht Work Engagement Scale (UWES short version) to measure work engagement (Schaufeli, Salanova, Gonzalez-Roma \& Bakker, 2002). On a 7-point Likert scale, respondents indicated how often they experience the feeling described by each statement with options ranging from 'never true of me' to 'almost always true of me'.

Burnout was measured by the two burnout scales: Exhaustion (Ex) (i.e. 'I feel emotionally drained from my work') and Cynicism (Cy) (i.e. 'I have become more cynical about whether my work contributes anything'). Because accumulating evidence suggests that exhaustion and cynicism constitute the core of burnout (Rothmann, 2008), the third dimension, lack of efficacy, was excluded here. Cronbach's $\alpha$ coefficients ranging from 0.71 to 0.90 have been reported for the subscales of the MBI (Maslach \& Jackson, 1986), while the reliability and validity have proven acceptable in South African and international studies (Leiter \& Schaufeli, 1996; Rothmann \& Joubert, 2007; Storm \& Rothman, 2003). In South African studies, the Cronbach's $\alpha$ coefficients varied from 0.86 to 0.88 for Exhaustion and from 0.74 to 0.80 for Cynicism (Rothmann, 2008; Rothmann \& Joubert, 2007). A Confirmatory Factor Analysis (CFA) conducted by Schaufeli, Salanova, Gonzalez-Roma and Bakker (2002) confirmed the factor structure of the MBI.

Because evidence suggests that Vigour (i.e. 'When I get up in the morning, I feel like going to work') and Dedication (i.e. 'I am proud of the work that I do') are core dimensions of engagement (Schaufeli \& Bakker, 2001), this study measured work engagement using these two dimensions. Various international and South African studies confirm the reliability and validity of the UWES (Coetzer \& Rothman, 2007; Naude \& Rothmann, 2004; Pienaar \& Sieberhagen, 2005; Schaufeli, Salanova, Gonzalez-Roma \& Bakker, 2002). Schaufeli, Salanova, Gonzalez-Roma and Bakker (2002) report an 
internal reliability coefficient for the three subscales ranging between 0.68 and 0.91, while Coetzer and Rothmann (2007) reported Cronbach's $\alpha$ of 0.80 (vigour), 0.87 (dedication) and 0.69 (absorption). The CFA conducted by Schaufeli and Bakker (2001) and Schaufeli, Salanova, Gonzalez-Roma and Bakker (2002) upon two samples confirmed the factor structure of the UWES, indicating a well-defined construct. For this questionnaire, relative fit indices (values greater than 0.90) were indicative of a good fit.

\section{Research procedure and ethical considerations}

Permission for the study was granted by the Director of the Business School and the Vice-Rector (Research). The researchers presented the research project to prospective candidates for management and leadership development programmes. After completing assessments for selection purposes, they were asked if they would participate in the study voluntarily. The aim of the research as well as the data-gathering instrument that participants would need to complete if they decided to participate in the project were discussed with them. Research participants were asked to sign a consent form relating to their participation in the research. The form included written assurance that their anonymity would be ensured and that no individual results would be reported in any publications. Only aggregated data relating to the total group would be reported and discussed. The questionnaires were collected immediately after the applicants completed them.

\section{Statistical analysis}

In order to determine the appropriateness of the unidimensional factor structure of the two instruments, CFA was conducted. All analyses related to the CFA were conducted using LISREL 8.80 (Jöreskog \& Sörbom, 2006). Several fit indices were used including the Satorra-Bentler scaled chi-square, Root Mean Square Error of Approximation (RMSEA) and the Comparative Fit Index (CFI). Values close to 0.95 for CFI were considered indicative of a good fit. It is suggested that values close to 0.06 are indicative of an acceptable fit for RMSEA, while values below 0.08 were acceptable for Standardised Root Mean Square Residual (SRMR) (Hu \& Bentler, 1999). Cronbach's alpha $(\alpha)$ was used to estimate the reliability of the measuring instruments. Reliability estimates of 0.70 and higher were indicative of good reliability. However, estimates as low as 0.60 may be acceptable when conducting exploratory research (Hair, Black, Babin, Anderson \& Tatham, 2006). Pearson productmoment correlation was used to investigate the degree to which the constructs measured by the FMI and MAAS were significantly correlated with burnout and work engagement. More specifically, stepwise multiple regression was used to determine whether the FMI and MAAS were significant predictors of burnout and engagement. CFA was used to investigate the degree to which the constructs measured by the FMI and MAAS were significantly correlated - providing evidence of convergent validity. Moderate correlations between 0.30 and 0.70 were deemed indicative of adequate convergent validity (Jackson, 2009).

\section{Results}

The results are discussed in terms of the suggested factor structure, goodness-of-fit and reliabilities of the instruments based on the current sample, the correlation between the MAAS and FMI as well as the correlations between the instruments and the different dimensions of burnout and work engagement.

\section{Factor structure}

The minimum average partial (MAP) test (Velicer, 1976) was used to determine the number of factors associated with each instrument. On the basis of the MAP test, a unidimensional factor structure was suggested for the FMI and MAAS.

The standardised factor loadings associated with the unidimensional factor structure of the FMI and MAAS are reported in Tables 1 and 2 .

All the standardised loadings are statistically significant, except for item 13, as shown in Table 1. In addition, the communality associated with item 13 is 0.002 . Hence, two different measurement models were tested for the FMI: one with all 14 items (FMI_ORIGINAL) and another with only the 13 significant items (FMI_REVISED).

All standardised loadings for the MAAS were statistically significant, as can be seen in Table 2 .

\section{Goodness-of-fit and reliability}

The goodness-of-fit statistics associated with the unidimensional factor structures are reported in Table 3.

From Table 3, it is evident that the MAAS and FMI fit the data well and these values provide evidence of an acceptable model fit. The CFI values are also indicative of an acceptable fit. It should be noted that the removal of the non-significant item 13 from the FMI-14 did not result in a substantial improvement in model fit. The MAAS seems to fit the data slightly better than the FMI when studying the RMSEA, CFI and SRMR.

\begin{tabular}{ll}
\multicolumn{2}{l}{ TABLE 1: Standardised factor loadings (FMI-14). } \\
\hline Item & Loading \\
\hline 1 & 0.49 \\
2 & 0.40 \\
3 & 0.48 \\
4 & 0.54 \\
5 & 0.61 \\
6 & 0.59 \\
7 & 0.66 \\
8 & 0.53 \\
9 & 0.61 \\
10 & 0.68 \\
11 & 0.57 \\
12 & 0.62 \\
13 & 0.08 \\
14 & 0.26 \\
\hline
\end{tabular}

Source: Buchheld, N., Grossman, P., \& Walach, H. (2001). Measuring mindfulness in insight meditation (Vipassana) and meditation-based psychotherapy: The development of the Freiburg Mindfulness Inventory (FMI). Journal of Meditation and Meditation Research, 1, 11-34 
TABLE 2: Standardised factor loadings (Mindful Attention Awareness Scale).

\begin{tabular}{ll}
\hline Item & Loading \\
\hline 1 & 0.39 \\
2 & 0.57 \\
3 & 0.58 \\
4 & 0.59 \\
5 & 0.60 \\
6 & 0.44 \\
7 & 0.76 \\
8 & 0.71 \\
9 & 0.61 \\
10 & 0.76 \\
11 & 0.56 \\
12 & 0.67 \\
13 & 0.57 \\
14 & 0.76 \\
15 & 0.56 \\
\hline
\end{tabular}

Source: Brown, K.W., \& Ryan, R.M. (2003). The benefits of being present: Mindfulness and its role in psychological well-being. Journal of Personality and Social Psychology, 84(4), 822-848. http://dx.doi.org/10.1037/0022-3514.84.4.822

TABLE 3: Goodness-of-fit: Freiburg Mindfulness Inventory and Mindful Attention Awareness Scale.

\begin{tabular}{llll}
\hline Fit statistics & FMI_ORIGINAL & FMI_REVISED & MAAS \\
\hline S-B $\chi^{2}$ & 284.82 & 246.02 & 281.23 \\
$d f$ & 77 & 65 & 90 \\
RMSEA & $0.074(0.065 ; 0.083)$ & $0.075(0.065 ; 0.085)$ & $0.065(0.057 ; 0.074)$ \\
CFI & 0.94 & 0.95 & 0.97 \\
SRMR & 0.061 & 0.060 & 0.054 \\
\hline
\end{tabular}

FMI, Freiburg Mindfulness Inventory; MAAS, Mindful Attention Awareness Scale. S-B $\chi^{2}$, Satorra-Bentler scaled chi-square; df, degrees of freedom; RMSEA, root mean square error of approximation; SRMR, Standardised Root Mean Square Residual; CFI, Comparative Fit Index.

Source: Buchheld, N., Grossman, P., \& Walach, H. (2001). Measuring mindfulness in insight meditation (Vipassana) and meditation-based psychotherapy: The development of the Freiburg Mindfulness Inventory (FMI). Journal of Meditation and Meditation Research, 1 11-34; Brown, K.W., \& Ryan, R.M. (2003). The benefits of being present: Mindfulness and its role in psychological well-being. Journal of Personality and Social Psychology, 84(4), 822-848. http://dx.doi.org/10.1037/0022-3514.84.4.822

Table 4 shows the reliability estimates.

From Table 4 , it is clear that the reliability estimates found by the current study are acceptable for the MAAS $(\alpha=0.89)$ and FMI $(\alpha=0.82)$.

Table 5 provides the correlation (phi) between the MAAS and FMI.

From Table 5, it is evident that there is a moderate correlation between the instruments (0.56). Moderate correlations between 0.30 and 0.70 are deemed indicative of adequate convergent validity (Jackson, 2009). It seems as if the instruments measure the same construct.

\section{The Freiburg Mindfulness Inventory and Mindful Attention Awareness Scale as predictors of burnout and engagement}

Table 6 shows the correlations between the mindfulness measures and burnout and work engagement.

It is evident from Table 6 that there are statistically significant negative correlations between the FMI and both dimensions of burnout (Emotional Exhaustion: $r=-0.19, p \leq 0.000$; Cynicism: $r=-0.23, p \leq 0.000)$. Also, there are statistically significant positive correlations between the FMI and both
TABLE 4: Reliabilities.

\begin{tabular}{lcc}
\hline Construct and/or dimension & Number of items & Cronbach's alpha $(\boldsymbol{\alpha})$ \\
\hline FMI_ORIGINAL & 14 & 0.823 \\
FMI_REVISED & 13 & 0.842 \\
MAAS & 15 & 0.896 \\
Emotional exhaustion & 5 & 0.892 \\
Cynicism & 4 & 0.928 \\
Vigour & 3 & 0.802 \\
Dedication & 3 & 0.895 \\
\hline
\end{tabular}

FMI, Freiburg Mindfulness Inventory; MAAS, Mindful Attention Awareness Scale.

Source: Buchheld, N., Grossman, P., \& Walach, H. (2001). Measuring mindfulness in insight meditation (Vipassana) and meditation-based psychotherapy: The development of the Freiburg Mindfulness Inventory (FMI). Journal of Meditation and Meditation Research, 1 11-34; Brown, K.W., \& Ryan, R.M. (2003). The benefits of being present: Mindfulness and its role in psychological well-being. Journal of Personality and Social Psychology, 84(4), 822-848. http://dx.doi.org/10.1037/0022-3514.84.4.822

TABLE 5: Correlation between the Mindful Attention Awareness Scale and Freiburg Mindfulness Inventory.

\begin{tabular}{lcc}
\hline Variable & MAAS & FMI \\
\hline MAAS & 1.00 & - \\
FMI & 0.56 & 1.00 \\
\hline
\end{tabular}

FMI, Freiburg Mindfulness Inventory; MAAS, Mindful Attention Awareness Scale.

Source: Buchheld, N., Grossman, P., \& Walach, H. (2001). Measuring mindfulness in insight meditation (Vipassana) and meditation-based psychotherapy: The development of the Freiburg Mindfulness Inventory (FMI). Journal of Meditation and Meditation Research, 1 11-34; Brown, K.W., \& Ryan, R.M. (2003). The benefits of being present: Mindfulness and its role in psychological well-being. Journal of Personality and Social Psychology, 84(4), 822-848. http://dx.doi.org/10.1037/0022-3514.84.4.822

TABLE 6: Correlations between mindfulness measures (Freiburg Mindfulness Inventory and Mindful Attention Awareness Scale) and dimensions of burnout and work engagement.

\begin{tabular}{llll}
\hline Variable & FMI_ORIGINAL & FMI_REVISED & MAAS \\
\hline Emotional exhaustion & -0.190 & -0.170 & -0.290 \\
Cynicism & -0.234 & -0.210 & -0.348 \\
Vigour & 0.345 & 0.336 & 0.354 \\
Dedication & 0.306 & 0.299 & 0.325 \\
Burnout & -0.232 & -0.208 & -0.349 \\
Engagement & 0.342 & 0.333 & 0.357 \\
\hline
\end{tabular}

FMI, Freiburg Mindfulness Inventory; MAAS, Mindful Attention Awareness Scale.

Source: Buchheld, N., Grossman, P., \& Walach, H. (2001). Measuring mindfulness in insight meditation (Vipassana) and meditation-based psychotherapy: The development of the Freiburg Mindfulness Inventory (FMI). Journal of Meditation and Meditation Research, 1, 11-34; Brown, KW \& Ryan RM. (2003). The benefits of 112 and its role in psychological well-being. Journal of Personality and Social Psychology, 84(4),

dimensions of work engagement (Vigour: $r=0.35, p \leq 0.000$; Dedication: $r=0.31, p \leq 0.000$ ). (It should be noted that the removal of item 13 did not result in a substantial decline in the correlations between the FMI_REVISED and the various dimensions of work engagement and burnout.)

Furthermore, there are statistically significant negative relationships between the MAAS and both dimensions of burnout (Emotional Exhaustion: $r=-0.29, p \leq 0.000$; Cynicism: $r=-0.35, p \leq 0.000$ ) and statistically significant positive relations between the MAAS and the two dimensions of work engagement (Vigour: $r=0.35, p \leq 0.000$; Dedication: $r=0.33, p \leq 0.000$ ).

In addition to the correlations, the stepwise multiple regression results (Tables 7 and 8) provide more appropriate evidence of the predictive validity of the FMI and MAAS being predictors of engagement and burnout.

From Table 7, it is clear that both the MAAS and the FMI are significant predictors of engagement. However, the MAAS 
TABLE 7: Stepwise multiple regression results: Freiburg Mindfulness Inventory, FMI REVISED and Mindful Attention Awareness Scale as predictors of engägement.

\begin{tabular}{lccc}
\hline Variable & Standardised beta coefficient & $\boldsymbol{t}$ & $\boldsymbol{p}$ \\
\hline MAAS & 0.248 & 5.211 & 0.000 \\
FMI & 0.217 & 4.564 & 0.000 \\
\hline
\end{tabular}

FMI, Freiburg Mindfulness Inventory; MAAS, Mindful Attention Awareness Scale.

Source: Buchheld, N., Grossman, P., \& Walach, H. (2001). Measuring mindfulness in insigh meditation (Vipassana) and meditation-based psychotherapy: The development of the Freiburg Mindfulness Inventory (FMI). Journal of Meditation and Meditation Research, 1 11-34; Brown, K.W., \& Ryan, R.M. (2003). The benefits of being present: Mindfulness and its role in psychological well-being. Journal of Personality and Social Psychology, 84(4) 822-848. http://dx.doi.org/10.1037/0022-3514.84.4.822

TABLE 8: Stepwise multiple regression results: Freiburg Mindfulness Inventory, FMI_REVISED and Mindful Attention Awareness Scale as predictors of burnout.

\begin{tabular}{lccc}
\hline Variable & Standardised beta coefficient & $\boldsymbol{t}$ & $\boldsymbol{p}$ \\
\hline MAAS & -0.305 & -8.293 & 0.000 \\
\hline
\end{tabular}

FMI, Freiburg Mindfulness Inventory; MAAS, Mindful Attention Awareness Scale.

explains $13 \%$ of the variance in engagement while the FMI explains $3 \%$ of the variance in engagement. The regression model is statistically significant $(F=48.043, p=0.000)$.

It is evident from Table 8 that the MAAS is the only significant predictor of burnout, explaining $12 \%$ of the variance. The regression model is statistically significant $(F=68.766, p=0.000)$.

From the above results (correlations and stepwise multiple regression), it is clear that the MAAS has higher correlations with, as well as better predictive validity of, burnout and work engagement.

\section{Discussion}

\section{Outline of results}

The first objective of the research was to compare the reliabilities and validity of the MAAS (short version) and FMI (short version) on a South African sample. With regard to the factor structure of these instruments, the MAP test suggested that the short versions of the MAAS and FMI are unidimensional in nature. With regard to the MAAS, these results are in line with previous research. Brown and Ryan (2003) found that the 15-item version of the MAAS yielded a unidimensional factor structure. This was confirmed by other researchers (Carlson \& Brown, 2005; Van Dam et al., 2010).

As mentioned before, the developers of the FMI (Buchheld et al., 2001) suggested that although the FMI (full and short version) consists of distinct components, it should be treated as a general (i.e. unidimensional) construct. Principal Component Analysis suggests that the 14-item version comprises one common factor (Walach et al., 2006). This has been confirmed by the results of the current study. However, the work of other researchers does not confirm this. Two other studies found it to be two dimensional, comprising a presence and acceptance factor with the number of items of each subscale differing between studies (Kohls, Sauer \& Walach, 2009; Ströhle, 2006). A study by Kohls et al. (2009) showed that a one-dimensional $(\alpha=0.83)$ and an alternative two-dimensional solution of the FMI-14 tested with a CFA and yielded suboptimal fit indices. An exploratory factor analysis resulted in a reduced eight-item version of the two-dimensional solution with better fit indices but low internal consistency. The factors could be identified as 'presence' and 'acceptance' (Kohls et al., 2009). Similarly, Sauer, Walach, Offenbächer, Siobhan and Kohls (2011) assessed the psychometric properties of the FMI-14 using a Rasch model approach in a cross-sectional design. The scale failed to show clear one-factoriality and a two-factorial solution appeared to fit the data better (Sauer et al., 2011). Although Kohls et al. (2009) did not report any problems with item 13 ('I am impatient with myself and others'), the current study found that item 13 had a non-significant loading on the unidimensional factor structure. This finding was also reported by Sauer et al. (2011) where their results showed that item 13 did not fit the Rasch model. A two-factorial solution without item 13, however, appeared to fit well. The item in question is negatively worded in the FMI-14. Although the current study reverse-scored item 13 , it still resulted in a nonsignificant loading.

In terms of the FMI-14, the goodness-of-fit statistics point to a measure that fitted the data fairly well. When comparing the results of the current study with those reported by Kohls et al. (2009), the CFI (0.94) versus that of the current study (0.97) is slightly lower while the RMSEA (0.074) versus the RMSEA of the current study (0.075) is slightly better. However, some validity limitations of the one- and two-factorial version of the scale were observed by Kohls et al. (2009). Their study demonstrates that the two-factorial version of the FMI-13 has acceptable approximation with Rasch requirements but is in need of further improvements, while the one-factorial solution did not fit well (Kohls et al., 2009).

Furthermore, with regard to the MAAS (short version), the goodness-of-fit statistics pointed to a measure that fitted the data well. The results from this study are comparable to those of Brown and Ryan (2003) who report an RMSEA of 0.058 versus the RMSEA of 0.065 found in the current study and a CFI of 0.91 versus 0.97 found in the current study. The developers of the questionnaire (Brown \& Ryan, 2003) reported a reliability of 0.87 in an adult sample. This value is almost exactly the same as that reported by the current study ( $\alpha=0.89$ ). In addition, the results obtained in the current study are slightly better than those found by MacKillop and Anderson (2007) who report an RMSEA of 0.071 and CFI of 0.91 . The reliability estimate for the MAAS is exactly the same: $\alpha=0.89$ for the current study and $\alpha=0.89$ from MacKillop and Anderson (2007). Therefore, the CFA points to a unidimensional factor structure for the MAAS (short version) with an acceptable reliability.

In summary, with regard to the current study, it is evident that the FMI and MAAS are acceptable measures of the constructs. Both instruments also show acceptable levels of reliability with the MAAS appearing to have a higher level of reliability than the FMI. This may be because of the fact that the MAAS consists of 15 items and the FMI of 14 items. In addition, the results suggest that both the FMI and MAAS can be treated as unidimensional constructs. 
The second objective of this study was to determine whether the MAAS (short version) and FMI-14 measure the same construct. The current study found a significant but moderate correlation (0.56) between these two instruments. This correlation is higher than that reported by Baer et al. (2006) who found a significant correlation of 0.31 between the FMI-14 and MAAS (short version). Sauer et al. (2011) are of the opinion that the FMI measures 'mindfulness', while the MAAS measures 'mindlessness'. According to these researchers, the latter 'may actually not be seen as the inverse conceptualization of mindfulness, but rather a (partly) different construct on its own right' (Sauer et al., 2011, p. 703). The MAAS is a measure of momentary mindful states (Brown et al., 2007) and focuses mostly on a lack of attentiveness to daily life (Grossman, 2008). According to Van Dam et al. (2010), the scale development of the MAAS is related to a specific cognitive theory and the items were chosen specifically to represent mindlessness. Brown and Ryan (2003, p. 826) opine that states reflecting less mindlessness are usually more accessible to most individuals, 'given that mindless states are more common than mindful states'.

The FMI appears to discriminate between experienced and novice meditators (Walach et al., 2006) but Belzer et al. (2012) challenged the construct validity of the FMI after determining with qualitative methods whether an adequate comprehension of the FMI items is independent of one's mindfulness experience. These researchers concluded that there is insufficient construct validity to use the current FMI in mindfulness-naive samples. According to Brown et al. (2007), the clinical approach to understanding the nature of mindfulness can be problematic. The different clinical approaches can create different definitions and operationalisations of mindfulness that reconcile with their particular treatment perspective and the outcomes they seek to obtain (Brown et al., 2007). Furthermore, 'clinically oriented conceptualisations of mindfulness can confound the description of the phenomenon with the methods through which it is fostered' (Brown et al., 2007, p. 215). For example, Kabat-Zinn's (2003) definition of mindfulness includes a wilful action or intention carried out to cultivate mindfulness. This action may reflect an individual's attitude towards current events and experience. On the other hand, according to Brown and Ryan (2003), the MAAS excludes attitudinal, motivational and other psychological phenomena directly linked to well-being or outcomes related to well-being (e.g. patience, acceptance). Although evidence shows the scale predicts various indicators of psychological well-being, it does not deal with well-being itself and therefore is not confounded with it.

The third objective of the study was to compare the FMI and MAAS in relation to burnout and work engagement (predictive validity). In terms of the correlations between mindfulness and burnout and mindfulness and work engagement, respectively, both constructs measured by the FMI and MAAS showed statistically significant relations with all dimensions of burnout and work engagement. Yet, it is evident that the MAAS has higher correlations with both dimensions of burnout and both dimensions of work engagement. Although research relating mindfulness to burnout and engagement within the workplace is limited, the results of these studies show that increased mindfulness can be linked to decreased emotional exhaustion/burnout (Hülsheger et al., 2013; Reb, Narayanan \& Chaturvedi, 2012; Roche et al. 2014; Roeser et al. 2013). In the current study, it was found that the MAAS was the only significant predictor of burnout explaining $12 \%$ of its variance.

Mindfulness has also been linked to increased work engagement. AMAAS study found that authentic functioning mediates the relationship between mindfulness and work engagement (Leroy et al., 2013). Krishnakumar and Robinson (2015) found that part-time employees with higher levels of dispositional mindfulness engaged less in counterproductive behaviour and were less prone to hostile feelings in the workplace. Furthermore, Depenbrock (n.d., p. 9) argues that 'the mindful state of consciousness is proposed to be positively related to work engagement as it is considered to help employees obtain, retain and protect resources needed to be energetic, enthusiastic and immersed in their job'. Again, the current study found that the MAAS was the best predictor of work engagement (12\% of the variance), while the FMI was the second best predictor of work engagement (explaining $3 \%$ of the variance).

\section{Practical implications}

Previous research has clearly shown that it is necessary to assess the psychometric properties of the currently available mindfulness instruments within different contexts and to publish the results. The current study has helped to fill this gap by examining the psychometric properties of the FMI and MAAS as measures of mindfulness on a South African sample. This study has confirmed the reliability and the unidimensional nature of these instruments. Although the current study found evidence of adequate convergent validity, researchers and practitioners still need to choose the measurement that is most applicable to their contexts. The results of the current study suggest that the MAAS may be the more appropriate measure to use within the context of the workplace given its predictive power in relation to burnout and work engagement.

As a developmental tool, both the MAAS and the FMI could also be quite useful when relating mindlessness or mindfulness to certain outcomes within the work situation. Various researchers agree that mindfulness can be developed (Youssef \& Luthans, 2007). Therefore, the developmental nature of mindfulness gives researchers the opportunity to establish and implement micro-interventions to focus on enhancing these positive strengths. Mindfulness training programmes revealed 'sustained enhancement in a variety of domains, including physical, psychological, cognitive, and conative realms' (Hyland et al., 2015, p. 15). It has been shown to reduce the extent to which employees experience emotional exhaustion (Hülsheger et al., 2013), especially when these jobs are in highly stressed contexts (Galantino, Baime, Maguire, Szapary \& Farrar, 2005). Chu (2010) found that higher levels of emotional intelligence (including 
self-awareness, self-management, social awareness and relationship management) are associated with increased mindfulness meditation experience while Chaskalson (2011) suggested that mindfulness is also likely to positively impact on other workplace outcomes, such as innovation, resilience, work engagement, productivity, absenteeism and turnover.

\section{Limitations and recommendations}

A limitation of the current study may be that the outcome variables (burnout and work engagement) used in this study are of a self-report nature. Grossman (2008) emphasises the importance of specific and objective external references to compare self-report responses. Perhaps other, more objective external measures of reference, such as productivity, absenteeism or turnover, which are not reliant on self-report measures, can be included in future studies of this nature.

More work is needed to collect additional evidence on the correlation between the FMI and MAAS by using different sample types within different work contexts in order to assess whether this relationship is consistently low. Further clarification of the construct definitions on which the development of the MAAS and FMI have been based is recommended as well as an investigation into the wording of the items that reflect these constructs. It may be that the wording of the MAAS items (e.g. 'I do jobs or tasks automatically, without being aware of what I am doing') may be easier to relate to in the work context, where individuals may be less exposed to mediation practices, than FMI items such as 'I sense my body, whether eating, cooking, cleaning or talking', which may be more relevant and easier to relate to outside the work context. Based on the statistically significant relationship between the constructs measured by the FMI and the MAAS and burnout and work engagement, it seems that mindfulness is a relevant construct within the work context. Yet, perhaps the development of a workplacespecific mindfulness questionnaire may be investigated in order to measure work mindfulness. Currently, based on the results of this study, it seems that the MAAS may be the better option of the two measures to use within the context of the workplace.

\section{Conclusion}

On the basis of this study, it can be concluded that the short versions of the FMI and MAAS are valid and reliable measures of mindfulness when conceptualised as unidimensional constructs. Because of the observed correlation between the MAAS (short version) and FMI (short version), it can be concluded that there is adequate evidence of convergent validity. This implies that there is considerable overlap between these two instruments. Although there is overlap between the two instruments, researchers will have to choose the most appropriate conceptualisation of mindfulness for their studies, especially when these studies are conducted within the workplace. In terms of the relationship between mindfulness and wellbeing (burnout and engagement), both instruments seem to be related to burnout and work engagement with the MAAS showing higher correlations, as well as better predictive validity.

\section{Acknowledgements Competing interests}

The authors declare that they have no financial or personal relationships which may have inappropriately influenced them in writing this article.

\section{Authors' contributions}

M.K. was responsible for the conceptualisation, literature review, and data-gathering, and P.N. executed the research design, statistical analysis, and also wrote that section of the article. Both M.K. and P.N. contributed to the discussion of the results and the conclusion.

\section{References}

Baer, R.A., Smith, G.T., \& Allen, K.B. (2004). Assessment of mindfulness by self-report: The Kentucky Inventory of Mindfulness Skills. Assessment, 11, 191-206. http:// dx.doi.org/10.1177/1073191104268029

Baer, R.A., Smith, G.T., Hopkins, J., Krietemeyer, J., \& Toney, L. (2006). Using self-report assessment methods to explore facets of mindfulness. Assessment, 13(1), $27-45$. $\mathrm{http}: / / \mathrm{dx}$.doi.org/10.1177/1073191105283504

Belzer, F., Schmidt, S., Lucius-Hoene, G., Schneider, J.F., Orellana-Rios, C., \& Sauer, S. (2012). Challenging the construct validity of mindfulness assessment - A cognitive interview study of the Freiburg Mindfulness Inventory. Mindfulness, 4, 33-44. http://dx.doi.org/10.1007/s12671-012-0165-7

Bergomi, C., Tschacher, W., \& Kupper, Z. (2012). The assessment of mindfulness with self-report measures: Existing scales and open issues. Mindfulness, 4, 191-202. http://dx.doi.org/10.1007/s12671-012-0110-9

Bishop, S.R., Lau, M., Shapiro, S.I., Carlson, L., Anderson, N.C., Carmody, J., et al. (2004). Mindfulness: A proposed operational definition. Clinical Psychology Science and Practice, 11, 230-241. http://dx.doi.org/10.1093/clipsy.bph077

Brown, K.W., Kasser, T., Ryan, R.M., Linley, P.A., \& Orzech, K. (2009). When what one has is enough: Mindfulness, financial desire discrepancy, and subjective wellbeing. Journal of Research in Personality, 43, 727-736. http://dx.doi. org/10.1016/j.jrp.2009.07.002

Brown, K.W., \& Ryan, R.M. (2003). The benefits of being present: Mindfulness and its role in psychological well-being. Journal of Personality and Social Psychology, 84(4), 822-848. http://dx.doi.org/10.1037/0022-3514.84.4.822

Brown, K.W., Ryan, R.M., \& Creswell, J.D. (2007). Mindfulness: Theoretical foundations and evidence for its salutary effects. Psychological Inquiry, 18(4), 211-237. http:// dx.doi.org/10.1080/10478400701598298

Buchheld, N., Grossman, P., \& Walach, H. (2001). Measuring mindfulness in insight meditation (Vipassana) and meditation-based psychotherapy: The development of the Freiburg Mindfulness Inventory (FMI). Journal of Meditation and Meditation Research, 1, 11-34.

Carlson, L.E., \& Brown, K.W. (2005). Validation of the Mindful Attention Awareness Scale in a cancer population. Journal of Psychosomatic Research, 58, 29-33. http://dx.doi.org/10.1016/j.jpsychores.2004.04.366

Chadwick, P., Hember, M., Symes, J., Peters, E., Kuipers, E., \& Dagnan, D. (2008). Responding mindfully to unpleasant thoughts and images: Reliability and validity Responding mindfully to unpleasant thoughts and images: Reliability and validity
of the Southampton Mindfulness Questionnaire (SMQ). British Journal of Clinical of the Southampton Mindfulness
Psychology, 47 (Pt4), 451-455.

Chaskalson, M. (2011). The mindful workplace: Developing resilient individuals and resonant organizations with MBSR. Oxford, UK: Wiley

Chu, L. (2010). The benefits of meditation vis-á-vis emotional intelligence, perceived stress and negative mental health. Stress and Health, 26(2), 169-180.

Christopher, M.S., Christopher, V., \& Charoensuk, S. (2009). Assessing western mindfulness among Thai Theravãda Buddhist Monks, Faculty Scholarship (SPP) Paper 2, Retrieved February 15, 2016, from http://commons.pacficu.edu/ sppfac/2

Coetzer, W.J., \& Rothmann, S. (2007). A psychometric evaluation of measures of affective well-being in an insurance company. South African Journal of Industria Psychology, 3(2), 7-15.

Crain, T.L., Schonert-Reichl, K.A., \& Roeser, R.W. (2016). Cultivating teacher mindfulness: Effects of a randomized controlled trail on work, home, and sleep outcomes. Journal of Occupational Health Psychology. http://dx.doi.org/10.1037/ ocp0000043

Dane, E. (2011). Paying attention to mindfulness and its effects on task performance in the workplace. Journal of Management, 37, 997-1018. http://dx.doi. org/10.1177/014920631036948 
Dane, E., \& Brummel, B.J. (2013). Examining workplace mindfulness and its relations to job performance and turnover intention. Human Relations, 67(1), 105-128. to job performance and turnover intention. H
http://dx.doi.org/10.1177/0018726713487753

Depenbrock, F. (n.d.). Being mindfully aware and engaged at work? The role of affect regulative processes for the relationship between daily levels of mindfulness and work engagement. Unpublished master's thesis, Maastricht University, Maastricht, The Netherlands.

Feldman, G.C., Hayes, A.M., Kumar, S.M., Greeson, J.M., \& Laurenceau, J.P. (2007). Mindfulness and emotion regulation: The development and initial validation of the cognitive and affective mindfulness scale-revised (CAMS-R). Journal of Psychopathology and Behavioural Assessment, 29, 177-190. http://dx.doi. org/10.1007/s10862-006-9035-8

Galantino, M.L., Baime, M., Maguire, M., Szapary, P.O., \& Farrar, J.T. (2005). Association of psychological and physiological measures of stress in healthcare professionals during an 8-week mindfulness meditation program: Mindfulness in practice. Stress and Health: Journal of the International Society for the Investigation of Stress, 21(4), 255-261. http://dx.doi.org/10.1002/smi.1062

Glomb, T.M., Duffy, M.K., Bono, J.E., \& Yang, T. (2011). Mindfulness at work. Personnel and Human Resources Management, 30, 115-157. http://dx.doi.org/10.1108/ S0742-7301(2011)0000030005

Grossman, P. (2008). On measuring mindfulness in psychosomatic and psychological research. Journal of Psychosomatic Research, 64, 405-408. http://dx.doi. org/10.1016/j.jpsychores.2008.02.001

Hair, J.F., Black, B., Babin, B., Anderson, R.E., \& Tatham, R.L. (2006). Multivariate dato analysis. (6th edn.). Upper Saddle River, NJ: Prentice Hall.

Hu, L., \& Bentler, P.M. (1999). Cut-off criteria for fit indexes in covariance structure analysis: Conventional criteria versus new alternatives. Structural Equation Modelling, 6, 1-55. http://dx.doi.org/10.1080/10705519909540118

Hülsheger, U.R., Alberts, H.J.E.M., Feinholdt, A., \& Lang, J.W.B. (2013). Benefits of mindfulness at work: The role of mindfulness in emotion regulation, emotional exhaustion, and job satisfaction. Journal of Applied Psychology, 98(2), 310-325. exhaustion, and job satisfaction. Jou

Hyland, P.K., Lee, R.A., \& Mills, M.J. (2015). Mindfulness at work: A new approach to improving individual and organizational performance. Industrial and improving individual and organizational performance. Industrial and
Organizational Psychology: Perspectives on Science and Practice, 8(4), 576-602. Organizational Psychology: Perspectives
http://dx.doi.org/10.1017/iop.2015.41

Jackson, S.L. (2009). Correlational methods and statistics. In S.L. Jackson (Ed.), Research methods and Statistics: A critical thinking approach (3rd edn., pp. 140Research methods and Statistics:
162). Belmont, CA: Wadsworth.

Jöreskog, K.G., \& Sörbom, D. (2006). LISREL 8.80 for Windows [Computer software]. Scientific Software International, Inc., Lincolnwood, IL.

Kabat-Zinn, J. (2003). Mindfulness-based interventions in context: Past, present and future. Clinical Psychology: Science and Practice, 10, 144-156. http://dx.doi. org/10.1093/clipsy.bpg016

Kohls, N., Sauer, S., \& Walach, H. (2009). Facets of mindfulness - Results of an online study investigating the Freiburg mindfulness inventory. Personality and Individual Differences, 46, 224-230. http://dx.doi.org/10.1016/j.paid.2008.10.009

Krasner, M.S., Epstein, R.M., Beckman, H., Suchman, A.L., Chapman, B., Mooney, C.J., et al. (2009). Association of an educational program in mindful communication with burnout, empathy, and attitudes among primary care physicians. Journa of the American Medical Association, 302(12), 1284-1293. http://dx.doi. org/10.1001/jama.2009.1384

Krishnakumar, S., \& Robinson, M.D. (2015). Maintaining an even keel: An affectmediated model of mindfulness and hostile work behavior. Emotion, 15(5), 579-589. http://dx.doi.org/10.1037/emo0000060

Langer, E.J., \& Moldoveanu, M., (2000). The construct of mindfulness. Journal of Social Issues, 56(1), 1-9. http://dx.doi.org/10.1111/0022-4537.00148

Lau, M.A., Bishop, S.R., Segal, Z.V., Buis, T., Anderson, N.D., Carlson, L., et al. (2006) The Toronto Mindfuness Psychology, 62(12), 1445-1467. http://dx.doi.org/10.1002/jclp.20326

Leigh, J., Bowen, S., \& Marlatt, G.A. (2005). Spirituality, mindfulness and substance abuse. Addict Behavior, 30, 1335-1341. http://dx.doi.org/10.1016/j.addbeh. 2005.01.010

Leiter, M.P., \& Schaufeli, W.B. (1996). Consistency of the burnout construct across occupations. Anxiety, Stress and Coping, 9, 229-243.

Leroy, H., Anseel, F., Dimitrova, N.G., \& Sels, L. (2013). Mindfulness, authentic functioning, and work engagement: A growth modelling approach. Journal of Vocational Behavior, 82, 238-247. http://dx.doi.org/10.1016/j.jvb.2013.01.012

Macey, W.H., \& Schneider, B. (2008). The meaning of employee engagement. Industrial and Organisational Psychology, 1, 3-30. http://dx.doi.org/10.1111/ j.1754-9434.2007.0002.x

Mackillop, J., \& Anderson, E.J. (2007). Further Psychometric validation of the Mindful Attention Awareness Scale (MAAS). Journal of Psychopathology and Behavioral Assessment, 29, 289-293. http://dx.doi.org/10.1007/s10862-007-9045-1

Maslach, C., \& Jackson, S.E. (1986). Maslach burnout inventory: Manual. (2nd edn.). Palo Alto, CA: Consulting Psychologists Press.
Maslach, C., Schaufeli, W.B., \& Leiter, M.P. (2001). Job burnout. Annual Review of Psychology, 52, 397-422. http://dx.doi.org/10.1146/annurev.psych.52.1.397

Modinos, G., Ormel, J., \& Aleman, A. (2010). Individual differences in dispositional and Affess and brain activity involved $\mathrm{http} / /$ dx doi.

Naudé, J.L.P., \& Rothmann, S. (2004). 'The validation of the Utrecht Work Engagement Scale for emergency medical technicians in Gauteng', South African Journal of Economic and Management Sciences, 7(3), 473-488.

Oman, D., Richards, T.A., Hedberg, J., \& Thoresen, C.E. (2008). Passage meditation improves caregiving self-efficacy among health professionals: A randomized trial and qualitative assessment. Journal of Health Psychology, 13, 1119-1135. http:// dx.doi.org/10.1177/1359105308095966

Pienaar, J., \& Sieberhagen, C. (2005). Burnout and engagement of student leaders in a higher education institution. South African Journal of Higher Education, 19, 115-167.

Reb, J., Narayanan, J., \& Chaturvedi, S. (2012). Leading mindfully: Two studies of the influence of supervisor trait mindfulness on employee well-being and performance. Mindfulness, 5(1), 36-45. http://dx.doi.org/10.1007/s12671-0120144-z

Reb, J., Narayanan, J., \& Ho, Z.W. (2013). Mindfulness at work: Antecedents and consequences of employee awareness and absent-mindedness. Mindfulness, 6(1), 111-122. http://dx.doi.org/10.1007/s12671-013-0236-4

Roche, M., Haar, J.M., \& Luthans, F. (2014). The role of mindfulness and psychological capital on the well-being of leaders. Management Department Faculty Publications, Paper 126, Retrieved February 17, 2016, from http://www. digitalcommons.unl.edu/managmentfacpub/126

Roeser, R.W., Schonert-Reichl, K.A., Jha, A., Cullen, M., Wallace, L., Wilensky, R., et al. (2013). Mindfulness training and reductions in teacher stress and burnout: Results from two randomized, waitlist-control field trials. Journal of Educational Psychology, 105(3), 787-804. http://dx.doi.org/10.1037/a0032093

Rothmann, S. (2008). Job satisfaction, occupational stress, burnout and work engagement as components of work-related wellbeing. South African Journal of Industrial Psychology, 34(3), 11-16. http://dx.doi.org/10.4102/sajip.v34i3.424

Rothmann, S., \& Joubert, J.H.M. (2007). Job demands, job resources, burnout and work engagement of managers at a platinum mine in the North West Province. South African Journal of Business Management, 38(3), 49-61.

Salanova, M., Schaufeli, W., Martinez, I., \& Breso, E. (2009). How obstacles and facilitators predict academic performance: The mediating role of study burnout and engagement. Anxiety, Stress and Coping, 23(1), 53-70. http://dx.doi.org/ 10.1080/10615800802609965

Sauer, S., Walach, H., Offenbächer, M., Siobhan, L., \& Kohls, N. (2011). Measuring mindfulness: A Rasch analysis of the Freiburg Mindfulness Inventory. Religions, 2 693-706. http://dx.doi.org/10.3390/rel2040693

Schaufeli, W.B., \& Bakker, A.B. (2001). Werk en welbevinden: Naar een positieve benadering in die Arbeids- en Gezondheidspsychologie [Work and wellbeing: Towards a positive occupational health psychology]. Gedrag en Organizatie, 14 229-253.

Schaufeli, W.B., Salanova, M., Gonzalez-Roma, V., \& Bakker, A.B. (2002). The measurement of burnout and engagement: A confirmatory factor analytic measurement of burnout and engagement: A confirmatory factor analytic
approach. Journal of Happiness Studies, 3, 71-92. http://dx.doi.org/10.1023/A: approach. Journ

Schaufeli, W.B., Martinez, I.M., Pinto, A.M., Salanova, M., \& Bakker, A.B. (2002). Burnout and engagement in university students: A cross-national study. Journal of Cross-Cultural Psychology, 33, 464-481. http://dx.doi.org/10.1177/00220 of Cross-Cultural

Shapiro, S.L., Carlson, L.E., Astin, J.A., \& Freedman, B. (2006). Mechanism of mindfulness. Journal of Clinical Psychology, 62(3), 373-386. http://dx.doi.org/10. $1002 /$ jclp.20237

Storm, K., \& Rothmann, S. (2003). The relationship between burnout, personality traits and coping strategies in a corporate pharmaceutical group. South African Journal of Industrial Psychology, 29(4), 35-42. http://dx.doi.org/10.4102/sajip. v29i4.128

Strőhle, G. (2006). Empirische Erfassung der Achtsamkeit. Unpublished master's thesis. University of Jena, Jena, Germany.

Van Dam, N.T., Earleywine, M., \& Borders, A. (2010). Measuring mindfulness? An item response theory analysis of the Mindful Attention Awareness Scale. Personality and Individual Differences, 49, 805-810. http://dx.doi.org/10.1016/j.paid.2010. 07.020

Velicer, W.F. (1976). Determining the number of components from a matrix of partial correlations. Psychometrika, 41, 321-327. http://dx.doi.org/10.1007/BF02293557

Walach, H., Buchheld, N., Buttenmüller, V., Kleinknecht, N., \& Schmidt, S. (2006). Measuring mindfulness - The Freiburg Mindfulness Inventory (FMI). Personality
and Individual Differences, 40,1543-1555. http://dx.doi.org/10.1016/j.paid.2005. and Indivio 11.025

Youssef, C.M., \& Luthans, F. (2007). Positive organizational behavior in the workplace: The impact of hope, optimism, and resilience. Journal of Management, 33(5), 774-800. http://dx.doi.org/10.1177/0149206307305562 